\title{
AN INVESTIGATION INTO THE ROLE OF GLUTEAL MUSCLE STRENGTH AND EMG ACTIVITY IN CONTROLLING HIP AND KNEE MOTION DURING LANDING TASKS \\ ABSTRACT
}

Objectives: To examine the relationship between gluteal muscle activity and strength and knee and hip biomechanics during single leg loading tasks

Design: Correlation study

Setting: University Biomechanics laboratory

Participants: 34 physically active, healthy participants, (17 males and 17 females).

Main outcome measures: gluteal muscle EMG activity; hip abduction and extension muscle strength; knee and hip angles and moments

Results: In females knee abduction moments and angles were strongly correlated to hip abduction strength across all tasks, whereas in males the relationships were less clear across tasks with both hip abduction strength and gluteus medius EMG activity showing the strongest relationships in specific tasks.

Conclusion: Hip and knee kinetic and kinematic variables related to the development of dynamic knee valgus would appear to be influenced by gluteal muscle strength and EMG activity. The level of influence varies across single leg squatting and landing tasks and varies between genders.

Keywords: Gluteal muscles; strength; hip and knee biomechanics 


\section{AN INVESTIGATION INTO THE ROLE OF GLUTEAL MUSCLE STRENGTH AND EMG ACTIVITY IN CONTROLLING HIP AND KNEE MOTION DURING LANDING TASKS}

\section{INTRODUCTION}

One biomechanical risk factor that has been widely researched is the dynamic knee valgus - a combination of hip adduction, internal hip rotation, knee abduction and tibial external rotation because of its potential relationship to significant knee injuries such $A C L$ rupture and Patellofemoral joint pain (Powers, 2010). Eccentric control of hip adduction and internal rotation has been identified as influencing dynamic knee valgus (Padua, et al., 2005; Powers, 2003). It has been hypothesised that greater external hip rotator and abductor strength may be able to resist excessive adduction and internal rotation moments, thus limiting dynamic knee valgus (Claiborne et al., 2006; Hollman et al., 2009). Conversely, weakness in the hip abductors and external rotators might lead to increased knee valgus motion and the potentially greater risk of Patellofemoral joint pain and $\mathrm{ACL}$ injury (Cashman, 2012; Powers, 2010).

The relationship between hip muscle function and dynamic knee valgus is therefore potentially very important, this motion is controlled principally by two muscles: gluteus maximus (G Max) and gluteus medius (G Med). The G Max largely extends and externally rotates the hip, while the G Med mainly abducts the hip, both in concert providing force in the opposite direction to counter the dynamic knee valgus collapse (Hollman et al., 2009). Neumann (2010) claims that the G Max has the greater force for producing external rotation compared to other hip muscles, while the G Med has the greatest role in producing abduction compared to the gluteus minimus and tensor fascia latae.

In the literature, the relationship between gluteal muscle strength and dynamic knee valgus is inconclusive. Several studies have shown a correlation between the knee abduction angle and weaker G Max and G Med (Claiborne et al 2006; Hollman et al 2013; Jacobs and Mattacola, 2005; Malloy et al 2016; Stickler et al 2015), the majority of these though only examined the relationship in female participants, or failed to investigate the 
impact of gender and used single leg squatting or single leg landing in the sagittal plane only. The studies of McCurdy et al (2014) found no relationship between gluteal muscle strength and knee valgus undertaking similar tasks. Previous studies have also demonstrated a relationship between gluteal muscle activation and dynamic knee valgus (Hollman et al., 2009; Hollman et al 2013; Hollman et al 2014; Zeller et al., 2003). Whilst Homan et al (2013) failed to find any relationship. Again, these studies were concentrated on female participants and single leg squat and single leg landing in the sagittal plane only. As the majority of $A C L$ injuries occur during movements in planes of movement other than the sagittal one (Koga et al 2010; Krosshaug et al 2007) having an understanding of muscle action, landing kinematics and kinetics in the sagittal plane alone, may not provide sufficient insight to understand the underpinning mechanisms involved in the faulty movement mechanics related to injury.

To date, there is only limited literature studying how G Max and G Med strength and the level of electromyography (EMG) activity are related to dynamic knee valgus motion during functional multi-directional single-leg landings in both male and female populations. Most studies in this area also only provide an assessment of the relationship between gluteal muscle function and knee valgus angles, with limited of no information on hip kinematics and kinetics or knee kinetics. The aim of this study is to investigate the relationship between G Max and G med strength and EMG activity and lower limb biomechanics, both kinetics and kinematics at the hip and knee, during both single leg squat and multidirectional single leg landings. It also aims to investigation if there are differences in these relationships between male and female subjects.

\section{METHODS}

\section{Participants}

A total of 34 active, healthy participants, comprising 17 males and 17 females, participated in this study. Females were aged $25.7(+/-4.5)$ years, with height $1.68(+/-0.05) m$, and mass $64.2(+/-7.3) \mathrm{kg}$ and males were aged $26.9(+/-3.8)$ years, with height $1.71(+/-$ 
$0.06) \mathrm{m}$, and mass $69.8(+/-6.6) \mathrm{kg}$. The number of participants was calculated apriori from a pilot work using G* Power 3 software to provide a statistical power of $80 \%$ and an effect size of 0.44 . All participants were free from injury at the time of testing, were physically active (participating in least 3 hours of exercise per week) and had no history of surgery or neurological impairment. All participants gave written informed consent and the study was approved by the university research ethics committee.

\section{Procedures}

\section{Isokinetic strength testing protocol}

For each participant, isokinetic muscle strength for both concentric and eccentric contractions were taken for both legs. Two different tests were carried out using the Biodex system 4, namely hip abduction and hip extension. To become familiar with the tests, participants practised every test with submaximal efforts. Participants were asked to perform three repetitions maximally for the test, with concentric contraction being followed by eccentric contractions, the peak value being record and used in the analysis. $60 \% / \mathrm{sec}$ was used as the testing speed. Five minutes rest was given between the two tasks. All measurements were carried out by the one examiner and peak torque was corrected automatically for gravity by Biodex software, by taking a static torque at $45^{\circ}$ of the hip extension test and $30^{\circ}$ for the hip abduction test prior to testing.

Hip abduction test: Subjects were placed in a side-lying position with the non-testing leg stabilised using straps around the thigh and above the ankle. The dynamometer's axis of rotation of movement was aligned medial to the greater trochanter. The lever arm provided resistance against the lateral aspect of the mid-thigh $(10 \mathrm{~cm}$ proximal to the knee joint). The range of motion when testing for hip abduction was from $0^{\circ}$ to $45^{\circ}$.

Hip extension test: Subjects were placed in a supine position with straps around their waist to stabilise the body. The dynamometer's axis of rotation of movement was aligned to the level of the greater trochanter. The lever provided resistance against the posterior mid-thigh ( $10 \mathrm{~cm}$ from posterior knee crease) and the knee flexed to $90^{\circ}$. The range of 
motion when testing hip extension was from $0^{\circ}$ to $30^{\circ}$. All strength data was normalised to body weight and presented as Nm.kg.

\section{Functional tasks:}

Single-leg Squat (SLS): In this study, subjects were instructed to stand in the middle of the force plate. The subject was then asked to squat down as far as possible to at least $45^{\circ}$ of knee flexion and no greater than $60^{\circ}$ while keeping the trunk as upright as possible (Zeller et al., 2003). Each trial was conducted over a period of five seconds, using an electronic counter. The first count was to initiate the squat, the third count indicated the lowest point of the squat and the fifth count indicated the end of the trial (Herrington, 2014).

Forward Land (FL): Subjects were instructed to stand on a step ( $30 \mathrm{~cm}$ height) and then stand on one leg and jump forward off it, landing on the force platform onto the same leg. The distance between the step and the platform was $30 \mathrm{~cm}$. The subject was asked to practise the task three times, to become familiar with it.

Side land with the force platform from inside of knee (SML): Subjects were instructed to stand on a step ( $30 \mathrm{~cm}$ height) and then, starting from a single-leg position, to perform a medial jump onto the force platform landing on the same leg. The distance between the step and the platform was $30 \mathrm{~cm}$. The subject was asked to practise the task before testing, to become familiar with it.

Side land with the force platform from outside of knee (SLL): Subjects were instructed to stand on a step ( $30 \mathrm{~cm}$ height). Starting from a single-leg position, they were asked to perform a lateral jump onto the force platform landing on the same leg. The distance between the step and the platform was $30 \mathrm{~cm}$. The subject was asked to practise the task before testing, to become familiar with it.

\section{D motion analysis protocol}


Fifteen cameras (Qualisys, Gothenburg, Sweden), sampling at $240 \mathrm{~Hz}$ in a motion analysis system, and one force platform (AMTI BP400600, USA), sampling at $1200 \mathrm{~Hz}$ and embedded into the floor, were used to collect kinematic and kinetic lower limb variables during different tasks. At the beginning of the procedure, 40 reflective markers were attached to both lower limbs' anatomical landmarks. Reflective markers were placed as follows: anterior superior iliac spines, posterior superior iliac spines, iliac crest, greater trochanters, medial and lateral femoral condyles, medial and lateral malleoli, posterior calcanei and the heads of the first, second and the fifth metatarsals in both limbs were placed on a standard training shoe. Finally, four rigid plates, each one consisting of four reflective markers, were attached to the antero-lateral aspect of the thigh and shank. The calibration anatomical systems technique (CAST) was used to determine each segment's movement during the trial (Cappozzo et al., 1996). The static trial position was calibrated as a subject's neutral alignment from standing over the force plate with weight distributed equally over both lower limbs. Following the satisfactory capture of all static markers, the anatomical markers were detached, keeping only 28 as tracking markers (16 markers over four cluster plates, eight markers attached to standard shoes and four markers on ASISs and PSISs). The participants wore standard lab shoes (New Balance, UK), to control the shoe-surface interface. The peak values (moments or angle) for all the variables of interest were used for further analysis and all moments presented are external.

\section{Electromyography Data Capture protocol}

Gluteus maximus (G Max) and gluteus medius ( $G$ Med) activity was recorded using a Noraxon Desktop DTS system (Noraxon USA Inc., model 586 Tele Myo DTS Desk Receiver), synchronised with the 3D capture and sampled at $1500 \mathrm{~Hz}$. A disposable, selfadhesive Noraxon surface electrode (Noraxon dual electrodes the diameter of each of these two circular conductive areas is $1 \mathrm{~cm}$, the inter-electrode distance is $2 \mathrm{~cm}$ ) was fixed over the relevant muscles. A surface electrode was prepared and placed, following the recommendations of the SENIAM project (SENIAM, 2011). Before electrode placement, the skin was shaved and cleaned using isopropyl alcohol. For the G Max, an electrode was 
placed at $50 \%$ of the distance between the sacral vertebrae and the greater trochanter. For the G Med, an electrode was placed at $50 \%$ distance from the line of the iliac crest to the greater trochanter. Before the testing session, participants maximum voluntary isometric contractions (MVIC) for each muscle were obtained so that data could be normalised. An MVIC for both G Max and G Med was performed according to the standard clinical testing methods defined by Norcross et al. (2010). For the G max, participants were prone with their hips extended $10^{\circ}$. For the $\mathrm{G}$ med, participants were on their side, with hips and knees in neutral and the hip at $10^{\circ}$ abduction to establish MVC.

\section{Data Processing}

Visual3D motion capture software (Version 4.21, C-Motion Inc., Rockville, MD, USA) was used to analyse and calculate the kinetic and kinematics data. A Butterworth 4th order bidirectional low-pass filter was used to filter the motion and force plate, with cut-off frequencies of $12 \mathrm{~Hz}$ and $25 \mathrm{~Hz}$ for kinematics and kinetics, respectively, and based on residual analysis (Yu et al., 1999). Joint kinematics were calculated using an X-Y-Z Euler rotation sequence. Joint kinetic data were calculated using three-dimensional inverse dynamics, and the joint data were normalised to body mass and presented as an external moment. Six degrees of freedom were determined by using CAST during all dynamic tasks (Cappozzo et al., 1996). Before dynamic trials, a static capture was obtained by standing on the force plates. The positions of these anatomical markers offered reference points for identifying bone movement through only the tracking markers set during the movement trials. Each segment of the pelvis, thigh, shank and foot was modelled to determine the proximal and distal joint/radius. The hip joint centre is automatically calculated by using ASIS and PSIS markers according to the regression equation from Bell et al., (1989).

Muscle activity profiles were used to determine any changes in the EMG activity of the muscles 100 milliseconds before landing and two seconds after initial contact, or until the participant was fully balanced; however, during squatting, EMG activity was recorded during ascent and descent until the subject fully extended the knee. EMG activity for each landing and squatting trial was synchronised with the task 3D data. EMG activity from the 
muscles ( $G$ Max, G Med) during these tasks was analysed as raw signals in Visual3D. The data were bandpass filtered $(25-450 \mathrm{~Hz})$ and a $60-\mathrm{Hz}$ notch filter was applied. A moving root mean squared (RMS) algorithm was used with a 100-millisecond window to produce a linear envelope. Corresponding muscle activity during the MVIC was also analysed in the same manner, and each set of data for each muscle, and each activity, was exported as a text file to Microsoft Excel 2010 (Microsoft, Washington, USA). The mean average of each maximum muscle activity from the three trials was taken, and this maximum was normalised to the corresponding MVIC.

\section{Statistical analysis}

The data were analysed using IBM SPSS Statistics 21 (IBM Corp, Armonk, NY, USA). First, a Shapiro-Wilk test was used to check whether the data were normally distributed or not (parametric or non-parametric). In addition, mean and standard deviations were calculated for each variable in each functional task. To explore the relationship between biomechanical variables and EMG activity for G Max, G Med, hip abduction isokinetic strength and hip extension isokinetic strength, Pearson's correlation coefficient ( $r$ ) was used for parametric data, and a Spearman's rank correlation $(\rho)$ for non-parametric data. Furthermore, the coefficient of determination $\left(R^{2}\right)$ was used in parametric data to represent the amount of variability in one screening test, which is explained by a second screening test (Swearingen et al., 2011). The classification of strength of correlation is small (0-0.3), moderate $(0.3-0.5)$, strong $(0.5-0.7)$ and very strong $(0.7-1)$, as described by Hopkins, et al (2009).

\section{RESULT}

Female Group: During the SLS task, a strong correlation was found between the hip adduction angle and G Med EMG activity $\left(r=.65, \mathrm{p}=.005, \mathrm{R}^{2}=0.42\right)$. The hip adduction angle inversely correlated with hip abduction eccentric strength $\left(r=-.59, p=.01, R^{2}=\right.$ 0.35). Hip adduction internal moment correlated with G Med EMG activity and inversely with hip abduction eccentric strength $\left(r=.52, p=.03, R^{2}=0.27\right.$ and $r=-.60, p=.01$, 
$\mathrm{R}^{2}=0.36$, respectively). Internal hip rotation moment negatively correlated with hip extension concentric strength $(\rho=-.60, p=.01)$. The knee abduction angle negatively correlated with hip abduction concentric strength $\left(r=-.55, p=.02, R^{2}=0.3\right)$ and hip extension eccentric strength $\left(r==-.5, p=.04, R^{2}=0.23\right)$. The knee abduction moment was inversely correlated with hip abduction concentric strength $\left(r=-.60, p=.01, R^{2}=\right.$ 0.36). Refer to table 1.

During the $\mathrm{FL}$, a very strong negative correlation was noted between hip abduction concentric strength and the knee abduction angle $(\rho=-.75, p=.005)$, G Max EMG activity correlated with the knee abduction angle $\left(r=.56 . p=.01, R^{2}=0.31\right)$. Knee abduction moment correlated with G Max EMG activity $(\rho=.5, p=.04)$, inversely with hip abduction concentric strength $(\rho=-.49, p=.04)$ and hip abduction eccentric strength $(\rho=-.54, p$ $=.02)$. Refer to table 1 .

During the SML task, a moderate negative correlation was noted between the internal hip rotation angle and hip abduction concentric strength $\left(r=-.5, p=.04, R^{2}=0.24\right)$. A strong negative correlation was observed between the knee abduction angle and hip abduction concentric strength $\left(r=-.55 . p=.02, R^{2}=0.3\right)$ and hip abduction eccentric strength $(r=$ -.56. $\left.\mathrm{p}=.01, \mathrm{R}^{2}=0.31\right)$. Refer to table 1 .

During the SLL task, strong negative correlations were noted between the knee abduction angle and hip abduction concentric strength $\left(r=-.73, p=.001 R^{2}=0.53\right)$ and hip abduction eccentric strength $\left(r=-.68, p=.002 R^{2}=0.46\right)$. Knee abduction moment correlated with hip extension concentric strength $(\rho=-.5, p=.004)$. Refer to table 1 .

Male Group: During the SLS task, a strong negative correlation was found between the hip adduction angle and hip extension concentric strength $\left(r=-.64, p=.005, R^{2}=0.41\right)$, hip extension eccentric strength $\left(r=-.62, p=.007, R^{2}=.38\right)$ and hip abduction eccentric strength $\left(r=-.60, p=.01, R^{2}=0.36\right)$, also moderately correlated with hip abduction concentric strength $\left(r=-.5, p=.04, R^{2}=0.23\right)$ along with $G$ Med EMG activity $(r=.56$, $\left.p=.01, R^{2}=0.31\right)$. The hip adduction moment correlated with $G$ med activity $(r=.62, p$ 
$\left.=.008, \mathrm{R}^{2}=0.38\right) . \mathrm{A}$ large correlation was noted between the knee abduction angle and G Med EMG activity $(\rho=.65, p=.004)$. Refer to table 2 .

During FL in the male group, the hip adduction angle had a strong negative correlation with hip abduction concentric $\left(r=-.60, p=.01, R^{2}=0.36\right)$ and hip abduction eccentric strength $\left(r=-.52, p=.03, R^{2}=0.27\right)$. Refer to table 2 .

During the SML task, correlations were noted between the hip adduction angle and G Med EMG activity $\left(r=.55, p=.02, R^{2}=0.3\right)$, hip abduction concentric strength $(r=-.56, p=$ $\left..01, R^{2}=.31\right)$ and hip abduction eccentric strength $\left(r=-.64, p=.003, R^{2}=0.41\right) . G$ Med EMG activity also strongly correlated with the hip adduction angle $(\rho=.67, p=.009)$. Other correlations were found between internal hip rotation moment and G Max EMG activity $(\rho=.5, p=.04)$, hip abduction eccentric $(r=-.59, p=.01)$ and hip extension eccentric strength $(r=-.54, p=.02)$. Refer to table 2 .

During the SLL task, the hip adduction angle strongly inversely correlated with hip abduction concentric strength $\left(r=-.55, p=.02, R^{2}=0.3\right)$ and abduction eccentric strength $\left(r=-.64, p=.001, R^{2}=0.41\right)$. A negative strong correlation was noted between internal hip rotation moment and hip abduction eccentric strength $\left(r=-.58, p=.01, R^{2}=0.34\right)$. Hip abduction eccentric strength correlated negatively with internal hip rotation moment $\left(r=-.58, p=.01, R^{2}=0.34\right) . A$ moderate correlation was noted between $G$ Med EMG activity and knee abduction moment $(\rho=.5, p=.003)$. Refer to table 2 .

\section{DISCUSSION}

The project's goal was to explore the relationship between strength and G Max and G Med EMG activity muscles and the lower limb biomechanical variables during single-leg squats and multi-directional single-leg landings in males and females. The study found moderate to strong relationships between gluteal muscles strength and EMG activity, and lower limb biomechanical variables depending on the tasks as presented in Tables 1 and 2 . Though on no occasion did the $r^{2}$ (were calculated) exceed 0.41 , so though these relationships were statistically significant they in no way explain fully what determines specific lower 
limb biomechanical variables variance. Some of the current findings were similar to the findings of previous studies, regardless of differences in the methodological tools and the participants.

In general, across the tasks when moderate or strong correlations were present for strength variables and either angles or moments these were negative, indicating as strength decreased the angle or moment concerned increased. This was not always the case for EMG activity were when present moderate or strong correlations to angles and moments were often positive, indicating increased EMG activity with increasing moments or angles. The later finding is supported by those of Homan et al (2013) who found greater G max and G med EMG activity in the low hip abductor and external rotator strength group, with increased knee abduction angles. They attributed this to the weaker individuals compensating for a lack of force production via heightened neural drive, being used in an attempt to recruit more muscle fibres to control the movement.

During SLS, in males, hip abduction and extension strength (eccentric and concentric) related to hip adduction angle (inversely), and G med EMG activity related to hip adduction angle and moment along with knee abduction angle. It would appear $\mathrm{G}$ med strength and activity play a significant role in controlling the hip in the frontal plane and so indirectly the knee frontal plane angle during SLS in males.

In males, during FL concentric and eccentric hip abduction strength were associated with hip abduction angle, with no further significant correlation to biomechanical variables during FL. These findings do not reflect those of McCurdy et al 2014 who found no single isolated strength variable to relate to knee abduction angle or those of Malloy et al 2016, who found hip external rotation not hip abduction strength to be related to knee abduction angle. The current study would appear to implicate the role of $\mathrm{G}$ med over $\mathrm{G}$ max in males controlling hip position during FL.

In males, during SML concentric and eccentric hip abduction strength were associated with hip abduction angle along with G med EMG activity. Concentric and eccentric hip abduction 
strength were also associated with knee abduction angle. Hip internal rotation angle was associated with hip abduction concentric strength, hip internal rotation moment was associated with hip abduction and extension eccentric strength and G max EMG activity. Itoh et al., (2016) found a moderate correlation between knee abduction angle and hip internal rotation moment and hip extension strength measured isometrically in male rugby players, which partial supports the current study findings. They also found hip external rotation strength to be correlated with knee abduction angle and moment. It would appear during SML in males both G med and G max appear to have significant roles.

During SLL, in males, concentric and eccentric hip abduction strength were associated with hip abduction angle, with hip abduction eccentric strength also being associated with hip adduction and internal rotation moments. G med EMG activity was associated with knee abduction moment. In the study of Itoh et al., (2016) hip external rotation strength was associated with knee abduction angle and moment, which contrasts with this study's finding, where G med would appear to have a more significant role as opposed to Gmax. It would appear during SLL G med would appear to have a greater influence performance than Glut max.

In the female cohort hip abduction eccentric strength was significantly related to both hip adduction angle and moment along with G med EMG activity, therefore in females $\mathrm{G}$ med strength and activity would appear to play a significant role in controlling the hip in the frontal plane during SLS. Hip abduction concentric strength in females was significantly related to both knee abduction angle and moment, which corresponds to the finding of Claiborne et al (2006) and Stickler et al (2015) who found concentric and isometric hip abduction strength (respectively) was related to knee abduction angle, neither of these studies assessed the relationship to moment. Hollman et al (2014) found G max EMG to be related to knee abduction angle which this study failed to do, though did find a relationship with concentric hip extensor strength, which also aligns with Willson et al (2006) finding of knee abduction angle being related to isometric hip external rotation 
strength (both functions being primarily undertaken by G max). It would appear in females both G med and G max appear to have significant roles in controlling SLS motion.

During FL in females, hip abduction concentric and eccentric strength were related to both knee abduction angle and moment, along with G max EMG activity. This aligns with the findings of Hollman et al (2013) who found G max EMG activity to be related to knee abduction angle. Though the finding is only partially support by those of Malloy et al (2016) with hip external rotation strength and Hollman et al (2013) hip extension strength being related to knee abduction angle, though both of these findings are likely to be related to the level of G max EMG activity, so could be linked to the findings of the present study. It would appear during FL it would appear both G med and G max have significant roles.

In females, hip abduction concentric and eccentric strength were related to knee abduction angle and hip abduction concentric strength with hip internal rotation angle during SML. Suzuki et al. (2015), used side medial landing from a 20-cm box to assess knee kinematics on 43 college basketball players (20 males and 23 females). The study reported that isometric hip extension and hip abduction strength negatively correlated with the knee abduction angle ( $r=-.48$ and -.46 , respectively), so aligns with the findings of the current study despite the methodological differences. It would appear during SML G med would appear to have a greater influence performance in females than Glut max.

In females, during SLL hip abduction concentric and eccentric strength were related to knee abduction angle, with hip extension concentric strength being associated with knee abduction moment. It would appear during SLL both G med and G max appear to have important roles in controlling motion.

This study is not without limitations, the limited literature in this area means the findings cannot be compared to other studies, so the findings cannot be validated. This is significant considering the levels of relationship found, at best variables in this study explained less than $40 \%$ of the variance in any parameter, it is therefore possible that more significant predictors of biomechanical performance during these tasks exist, which this study did not 
investigate and remain to be identified. The tasks themselves, though having some functional qualities, are still undertaken in the closed controlled environment of a biomechanics laboratory and so may lack ecological validity when compared to having to perform them in chaotic sporting contexts. One significant predictor of performance could be gender, a further limitation of this study was that no comparison was made between genders, so no inferences can be made about differences between the genders. Future study should attempt to assess the impact of gender on any differences in performance between the tasks.

\section{CONCLUSION}

Hip and knee kinetic and kinematic variables related to the development of dynamic knee valgus would appear to be influenced by gluteal muscle strength and EMG activity. The level of influence varies across single leg squatting and landing tasks and would appear superficially to differ between genders, though this was not statistically analysed. It would appear that $\mathrm{G}$ med (hip abductor muscles) strength and activity have a more important role than $\mathrm{G}$ max (hip extensor (external rotator) muscles) in male subjects in influencing the nature of the motion occurring across all tasks. In females both $\mathrm{G}$ med and $\mathrm{G}$ max would appear to have an equally influential role across all tasks. This information could be used to drive future gender specific strength training programmes to reduce dynamic knee valgus. 


\section{REFERENCES}

Bell L, Brand A, and Pedersen, R. (1989). Prediction of hip-joint center location from external landmarks. Human Movement Science, 8, 3-16

Cappozzo, A., Catani, F., Leardini, A., Benedetti, M. G., and Della Croce, U. (1996). Position and orientation in space of bones during movement: experimental artefacts. Clinical Biomechanics, 11(2), 90-100.

Cashman, G. E. (2012). The effect of weak hip abductors or external rotators on knee valgus kinematics in healthy subjects: a systematic review. Journal of Sport Rehabilitation, $21(3), 273-84$.

Claiborne, T. L., Armstrong, C. W., Gandhi, V., and Pincivero, D. M. (2006). Relationship between hip and knee strength and knee valgus during a single leg squat. Journal of Applied Biomechanics, 22(1), 41-50.

Hollman, J. H., Galardi, C. M., Lin, I. H., Voth, B. C., and Whitmarsh, C. L. (2014). Frontal and transverse plane hip kinematics and gluteus maximus recruitment correlate with frontal plane knee kinematics during single-leg squat tests in women. Clinical Biomechanics, 29(4), 468-474.

Hollman, J. H., Ginos, B. E., Kozuchowski, J., Vaughn, A. S., Krause, D. A., and Youdas, J. W. (2009). Relationships between knee valgus, hip-muscle strength, and hip-muscle recruitment during a single-limb step-down. Journal of Sport Rehabilitation, 18(1), 104.

Hollman, J. H., Hohl, J. M., Kraft, J. L., Strauss, J. D., and Traver, K. J. (2013). Modulation of frontal-plane knee kinematics by hip-extensor strength and gluteus maximus recruitment during a jump-landing task in healthy women. Journal of Sport Rehabilitation, 22(3), 184-190.

Homan, K. J., Norcross, M. F., Goerger, B. M., Prentice, W. E., and Blackburn, J. T. (2013). The influence of hip strength on gluteal activity and lower extremity kinematics. Journal of Electromyography and Kinesiology, 23(2), 411-415 
Hopkins, W., Marshall, S., Batterham, A., \& Hanin, J. (2009). Progressive statistics for studies in sports medicine and exercise science. Medicine and Science in Sports and Exercise, 41(1), 3-12

Itoh, H., Takiguchi, K., Shibata, Y., Okubo, S., Yoshiya, S., and Kuroda, R. (2016). Correlation between hip function and knee kinematics evaluated by three-dimensional motion analysis during lateral and medial side-hopping, Journal of Physical Therapy Science 28, 2461-2467

Jacobs, C., and Mattacola, C. (2005). Sex differences in eccentric hip-abductor strength and knee-joint kinematics when landing from a jump. Journal of Sport Rehabilitation, $14(4), 346-352$

Koga, H., Nakamae, A., Shima, Y., Iwasa, J., Myklebust, G., Engebretsen, L., Bahr, R., Krosshaug, T. (2010) Mechanisms for noncontact anterior cruciate ligament injuries: knee joint kinematics in 10 injury situations from female team handball and basketball. American Journal of Sports Medicine. 38(11), 2218-25

Krosshaug, T., Nakamae, A., Boden, B., Engebretsen, L., Smith, G., Slauterbeck J., Hewett T., Bahr R. (2007) Mechanisms of anterior cruciate ligament injury in basketball: video analysis of 39 cases. American Journal of Sports medicine.2007 35(3), 359-67.

Malloy, P., Morgan, A., Meinerz, C., Geiser, C. F., Atc, M. P., and Kipp, K. (2017). Hip external rotator strength is associated with better dynamic control of the lower extremity during landing tasks, Journal of Sports Rehabilitation 30(1), 282-291

McCurdy, K., Walker, J., Armstrong, R., Langford, G. (2014) Relationship between selected measures of strength and hip and knee excursion during unilateral and bilateral landings in women. Journal of Strength and Conditioning Research 28(9), 2429-36

Neumann, D. A. (2010). Kinesiology of the hip: a focus on muscular actions. Journal of Orthopaedic and Sports Physical Therapy, 40(2), 82-94 
Norcross, M. F., Blackburn, J. T., and Goerger, B. M. (2010). Reliability and interpretation of single leg stance and maximum voluntary isometric contraction methods of electromyography normalization. Journal of Electromyography and Kinesiology, 20(3), $420-425$

Padua, D. A., Carcia, C. R., Arnold, B. L., and Granata, K. P. (2005). Gender Differences in Leg Stiffness and Stiffness Recruitment Strategy During Two-Legged Hopping. Journal of Motor Behavior, 37(2), 111-126

Powers, C. M. (2003). The influence of altered lower-extremity kinematics on patellofemoral joint dysfunction: a theoretical perspective. Journal of Orthopaedic and Sports Physical Therapy, 33(11), 639-646.

Powers, C. M. (2010). The influence of abnormal hip mechanics on knee injury: a biomechanical perspective. Journal of Orthopaedic and Sports Physical Therapy, 40(2), $42-51$

SENIAM. (2011). http://www.seniam.org/.

Stickler, L., Finley, M., and Gulgin, H. (2015). Relationship between hip and core strength and frontal plane alignment during a single leg squat. Physical Therapy in Sport, 16(1), $66-71$

Suzuki, H., Omori, G., Uematsu, D., Nishino, K., and Endo, N. (2015). the Influence of Hip Strength on Knee Kinematics During a Single-Legged Medial Drop Landing Among Competitive Collegiate Basketball Players. International Journal of Sports Physical Therapy, 10(5), 592-601

Swearingen, J., Lawrence, E., Stevens, J., Jackson, C., Waggy, C., and Davis, D. S. (2011). Correlation of single leg vertical jump, single leg hop for distance, and single leg hop for time. Physical Therapy in Sport, 12(4), 194-198 
Willson, J. D., Ireland, M. L., and Davis, I. (2006). Core strength and lower extremity alignment during single leg squats. Medicine and Science in Sports and Exercise, 38(5), $945-52$

Yu, B., Gabriel, D., Noble, L., and An, K. N. (1999). Estimate of the optimum cutoff frequency for the Butterworth low-pass digital filter. Journal of Applied Biomechanics, $15(3), 318-329$

Zeller, B. L., McCrory, J. L., Kibler, W. Ben, and Uhl, T. L. (2003). Differences in Kinematics and Electromyographic Activity Between Men and Women during the Single-Legged Squat. American Journal of Sports Medicine, 31(3), 449-456 
Table 1: Moderate or stronger significant correlations ( $\rho$ or $r>0.5$ ) for each biomechanical parameter and task in females

\begin{tabular}{|c|c|c|c|c|}
\hline $\begin{array}{l}\text { Task } \\
\text { correlations } \\
\text { (Females) }\end{array}$ & SLS & $\mathbf{F L}$ & SLL & SML \\
\hline \multicolumn{5}{|l|}{$\begin{array}{l}\text { Biomechanical } \\
\text { variables }\end{array}$} \\
\hline $\begin{array}{c}\text { Hip adduction } \\
\text { angle }\end{array}$ & $\begin{array}{ll} & \text { Gluteus } \\
\text { Medius } \\
\text { emg } \\
\text { - Hip } \\
\text { abduction } \\
\text { eccentric } \\
\text { strength } \\
\end{array}$ & & & \\
\hline $\begin{array}{l}\text { Hip adduction } \\
\text { moment }\end{array}$ & $\begin{array}{ll}\text { - } & \text { Gluteus } \\
\text { Medius } \\
\text { emg } \\
\text { - Hip } \\
\text { abduction } \\
\text { eccentric } \\
\text { strength } \\
\end{array}$ & & & \\
\hline $\begin{array}{l}\text { Hip internal } \\
\text { rotation angle }\end{array}$ & & & & $\begin{array}{ll}- & \text { Hip } \\
& \text { abduction } \\
\text { concentric } \\
\text { strength }\end{array}$ \\
\hline $\begin{array}{c}\text { Hip internal } \\
\text { rotation } \\
\text { moment }\end{array}$ & $\begin{array}{ll}\text { - Hip } \\
\text { extension } \\
\text { concentric } \\
\text { strength } \\
\end{array}$ & & & \\
\hline $\begin{array}{c}\text { Knee abduction } \\
\text { angle }\end{array}$ & $\begin{array}{ll} & \text { Hip } \\
\text { abduction } \\
\text { concentric } \\
\text { strength } \\
\text { Hip } \\
\text { extension } \\
\text { concentric } \\
\text { strength }\end{array}$ & $\begin{array}{ll}\text { - } & \text { Hip } \\
\text { abduction } \\
\text { concentric } \\
\text { strength } \\
\text { - } \text { Gluteus } \\
\text { Maximus } \\
\text { emg }\end{array}$ & $\begin{array}{ll}\text { - } & \text { Hip } \\
\text { abduction } \\
\text { concentric } \\
\text { strength } \\
\text { - } \\
\text { Hip } \\
\text { abduction } \\
\text { eccentric } \\
\text { strength }\end{array}$ & $\begin{array}{ll}- & \text { Hip } \\
\text { abduction } \\
\text { concentric } \\
\text { strength } \\
\text { - Hip } \\
\text { abduction } \\
\text { eccentric } \\
\text { strength }\end{array}$ \\
\hline $\begin{array}{c}\text { Knee } \\
\text { Abduction } \\
\text { moment }\end{array}$ & $\begin{array}{ll}\text { - } & \text { Hip } \\
\text { abduction } \\
\text { concentric } \\
\text { strength }\end{array}$ & $\begin{array}{ll}\text { - } & \text { Hip } \\
\text { abduction } \\
\text { concentric } \\
\text { strength } \\
\text { - Hip } \\
\text { abduction } \\
\text { eccentric } \\
\text { strength } \\
\text { - Gluteus } \\
\text { Maximus } \\
\text { emg }\end{array}$ & $\begin{array}{ll}\text { - } & \text { Hip } \\
\text { extension } \\
\text { concentric } \\
\text { strength }\end{array}$ & \\
\hline
\end{tabular}

SLS: single leg squat. FL: forward single leg land. SLL: lateral single leg land. SML: medial single leg land 
Table 2: Moderate or stronger significant correlations ( $\rho$ or $r>0.5$ ) for each biomechanical parameter and task in males

\begin{tabular}{|c|c|c|c|c|}
\hline $\begin{array}{l}\text { Task } \\
\text { correlations } \\
\text { (males) }\end{array}$ & SLS & FL & SLL & SML \\
\hline \multicolumn{5}{|l|}{$\begin{array}{l}\text { Biomechanical } \\
\text { variable }\end{array}$} \\
\hline $\begin{array}{c}\text { Hip adduction } \\
\text { angle }\end{array}$ & $\begin{array}{ll}\text { - } & \text { Hip } \\
\text { abduction } \\
\text { eccentric } \\
\text { strength } \\
\text { - Hip } \\
\text { abduction } \\
\text { concentric } \\
\text { strength } \\
\text { - } \text { Hip } \\
\text { extension } \\
\text { eccentric } \\
\text { strength } \\
\text { - Hip } \\
\text { extension } \\
\text { concentric } \\
\text { strength } \\
\text { Gluteus } \\
\text { Medius } \\
\text { emg }\end{array}$ & $\begin{array}{ll} & \text { Hip } \\
\text { abduction } \\
\text { eccentric } \\
\text { strength } \\
\text { - Hip } \\
\text { abduction } \\
\text { concentric } \\
\text { strength }\end{array}$ & $\begin{array}{ll}\text { - } & \text { Hip } \\
\text { abduction } \\
\text { eccentric } \\
\text { strength } \\
\text { - } & \text { Hip } \\
\text { abduction } \\
\text { concentric } \\
\text { strength }\end{array}$ & $\begin{array}{ll}\text { - } & \text { Hip } \\
& \text { abduction } \\
\text { eccentric } \\
\text { strength } \\
\text { - Hip } \\
\text { abduction } \\
\text { concentric } \\
\text { strength } \\
\text { - Gluteus } \\
\text { Medius emg }\end{array}$ \\
\hline $\begin{array}{l}\text { Hip adduction } \\
\text { moment }\end{array}$ & $\begin{array}{ll}\text { Gluteus } \\
\text { Medius } \\
\text { emg }\end{array}$ & & $\begin{array}{ll}- & \text { Hip } \\
\text { abduction } \\
\text { eccentric } \\
\text { strength }\end{array}$ & \\
\hline $\begin{array}{l}\text { Hip internal } \\
\text { rotation angle }\end{array}$ & & & & $\begin{array}{ll}\text { - } & \text { Hip } \\
\text { abduction } \\
\text { concentric } \\
\text { strength } \\
\end{array}$ \\
\hline $\begin{array}{l}\text { Hip internal } \\
\text { rotation } \\
\text { moment }\end{array}$ & & & $\begin{array}{ll}\text { - Hip } \\
\text { abduction } \\
\text { eccentric } \\
\text { strength }\end{array}$ & $\begin{array}{ll}- & \text { Gluteus } \\
& \text { Maximus } \\
\text { emg } \\
\text { - } & \text { Hip } \\
\text { abduction } \\
\text { eccentric } \\
\text { strength } \\
\text { - Hip } \\
\text { extension } \\
\text { eccentric } \\
\text { strength } \\
\end{array}$ \\
\hline $\begin{array}{c}\text { Knee } \\
\text { abduction } \\
\text { angle }\end{array}$ & $\begin{array}{ll} & \text { Gluteus } \\
& \text { Medius } \\
\text { emg }\end{array}$ & & & $\begin{array}{ll}\text { - } & \text { Hip } \\
\text { abduction } \\
\text { concentric } \\
\text { strength } \\
\text { - Hip } \\
\text { abduction } \\
\text { eccentric } \\
\text { strength }\end{array}$ \\
\hline
\end{tabular}




\begin{tabular}{|c|l|l|l|l|}
\hline $\begin{array}{c}\text { Knee } \\
\text { Abduction } \\
\text { moment }\end{array}$ & & $\bullet$ & $\begin{array}{l}\text { Gluteus } \\
\text { Medius emg }\end{array}$ & \\
\hline
\end{tabular}

SLS: single leg squat. FL: forward single leg land. SLL: lateral single leg land. SML: medial single leg land 